\title{
Kentsel Yeşil Altyapıların Önemli Bir Bileşeni Olan Kent Ormanlarının Sağladığı Ekosistem Servisleri "Kafkasör Kent Ormanı Örneği”"
}

\author{
Banu KARAŞAH* \\ Artvin Çoruh Üniversitesi Sanat ve Tasarım Fakültesi Peyzaj Mimarlı̆̆ Bölümü, Arhavi Yerleşkesi, Artvin, Türkiye
}

Atıf yapmak için: Karaşah, B. (2020). Kentsel Yeşil Altyapıların Önemli Bir Bileşeni Olan Kent Ormanlarının Sağladığı Ekosistem Servisleri "Kafkasör Kent Ormanı Örneği”. Anadolu Çev. ve Hay. Dergisi, 5(4), 668-675.

How to cite: Karaşah, B. (2020). Ecosystem Services Provided by Urban Forests as an Important Component of Urban Green Infrastructures "Case of Kafkasör Urban Forest ”. J. Anatolian Env. and Anim. Sciences, 5(4), 668-675.

: https://orcid.org/0000-0001-5079-5313
Öz: Ekosistem servisleri, insanların doğal veya tasarlanmış alanlardan doğrudan veya dolaylı olarak elde ettikleri fayda ve ürünler olarak tanımlanmaktadır. Kentsel yeşil altyapıların çevresel ve sosyal birçok faydası vardır. Kentsel yeşil altyapıların önemli bir parçası olan kent ormanları, kent çevrelerinin homojenliğini kıran, kentin estetiğine katkı sağlayan, kentlerin yeșil dokusunu güçlendiren, kente ve kentlilere rekreasyonel açıdan aktivite alanları sunan ve kent sakinlerine fiziksel ve ruhsal açıdan birçok ekosistem servisi sağlayan aktif yeșil alanlardır. Bu çalıșmada, Artvin kentine ve kent sakinlerine geniş bir yelpazede ekosistem servisi sağlayan Kafkasör Kent Ormanı çalışma alanı olarak seçilmiş ve kent ormanının sağladığ1 ekosistem servislerinin ortaya konulması amaçlanmıștır. Kafkasör Kent Ormanı'nın kaynak sağlayan (gıda, dekoratif kaynaklar, biyolojik hammadde, biyokimyasal ve tıbbi ürünler), düzenleyici (hava kalitesini düzenleme, iklim düzenleme su akışı ve erozyon kontrolü, polenleme), destekleyici (fotosentez, besin ve su döngüsünü destekleme) ve kültürel ekosistem servisleri (eğitim, bilgi sistemi, ilham, estetik değerler, sosyal ilişkiler, yer ve mekan hissi, rekreasyon ekoturizm, sağlık, ekonomi, doğayla bağlantı, duyusal deneyimler) açısından birçok servisi sunduğu tespit edilmiștir. Çalıșmada kültürel ekosistem servisleri bağlamında görülen bazı eksikliklerin giderilmesine yönelik önerilerde bulunulmuştur. Ekosistem servislerinin sürekliliğinin sağlanması ve insanların bu servislerden en iyi șekilde faydalanabilmesi için alanlara ilișkin doğru stratejilerin belirlenmesi ve planlamaların bu doğrultuda yapılması önem arz etmektedir.

Anahtar kelimeler: Artvin, ekosistem servisleri, kafkasör kent ormanı, kent ormanı, kentsel yeșil altyapilar.

\section{Ecosystem Services Provided by Urban Forests as an Important Component of Urban Green Infrastructures "Case of Kafkasör Urban Forest"}

*Corresponding author's: Banu KARASAH

Department of Landscape Architecture, Faculty of Arts and Design, Artvin Coruh University, Arhavi Campus, Artvin, Turkey. $\triangle$ : banukarasah@artvin.edu.tr

Mobile telephone: +90 (505) 3839815

Telephone : $\quad:+90(466) 2151099 / 3462$

Fax : $\quad+90(466) 2151050$
Abstract: Ecosystem services are defined as benefits and products that people obtain from natural or designed areas directly or indirectly. Urban green infrastructures have many environmental and social benefits. Urban forests as an important part of urban green infrastructures are active green areas that break the homogeneity of urban environments, contribute to the aesthetics of the cities, strengthen the green texture of the cities, offer recreational activities to the city and city-dwellers and provide many ecosystem services to city-dwellers in terms of physical and mental aspects. In this study, Kafkasör Urban Forest, which provides a wide range of ecosystem services to Artvin city and its residents, was chosen as a study area and it was aimed to reveal the ecosystem services provided by this urban forest. It has been determined that Kafkasör Urban Forest offers many services in terms of provisioning (food, ornamental resources, fiber, biochemicals and pharmaceuticals), regulating (air quality regulation, climate regulation, water purification and erosion regulation, pollination), supporting (photosynthesis, nutrient and water cycling) and cultural ecosystem services (educational, knowledge system, inspiration, aesthetic values, social relations, sense of place, recreation and ecotourism, health, economic, connection to nature, sensory experiences). Some suggestions were proposed to overcome some deficiencies in the context of cultural ecosystem services. In order to ensure the sustainability of ecosystem services and for people to benefit from these services ideally, it is important to determine the correct strategies and planning should be done in this direction.

Keywords: Artvin, ecosystem services, Kafkasör urban forest, urban forest, urban green infrastructures. 


\section{GİRIŞ}

2050 yılında dünya nüfusunun \% 68 'inin kentleşmiş alanlarda yaşayacağı tahmin edilmektedir. Kentleşmenin istihdam firsatlarını arttırması ve yaşam standartlarını iyileştirmesi gibi olumlu etkilerinin yanı sıra kentsel yaşamla ilişkili olumsuz etkileri de vardır (Riva vd., 2009). Örneğin çalışmalarda kentsel alanlarda yaşayan insanların, kırsal alanlarda yaşayan insanlardan daha fazla sağlık sıkıntısı çektiği ifade edilmiştir (Harriss \& Hawton, 2011; Rajoo vd., 2020).

Çok sayıda çalışma, yeşil altyapıların önemli bir parçası olan kentsel yeşil alanların çevresel ve sosyal faydaları olduğunu göstermektedir. Kentsel yeşil alanlar tarafindan sağlanan çevresel faydalar arasında yalnızca kentsel ekolojiyi desteklemek değil, aynı zamanda halk sağlığını korumak da yer almaktadır. Ayrıca kentsel yeşil alanlar havayı filtrelemekte (Akbari, 2002), gürültüyü azaltmakta (Margaritis \& Kang, 2017), kirliliği azaltmakta (Grote vd., 2016) ve yağmur suyu akışı problemini çözmekte (Zhang vd., 2012) gölge (Lafortezza vd., 2009) ve yiyecek sağlamakta (Barthel vd., 2015) ve mikroklimayı düzenlenmektedir (La Rosa, 2014; Shin \& Lee, 2005). Kentte yaşayanlar için sosyal faydaları ise; stresi azaltarak fiziksel ve ruhsal sağlığı iyileştirmek (Van den Berg vd., 2010), doğada geçirilen serbest zamanı (Carrus vd., 2015) ve sosyal kaynaşmayı arttırmaktır (De Vries vd., 2013). Kentsel yeşil alanlar, suç ve şiddetini azaltma (Bogar \& Beyer, 2015), sağlık hizmetlerini iyileştirme (Conradson, 2005) ve saldırgan davranışı azaltma (Ulrich vd., 2018) potansiyeline de sahiptir (Ma, 2020).

Kent ormanları, yeşil altyapının önemli bir bileşenidir. Kent ormanları, şehirleri ve kasabaları sakinleri ve ziyaretçileri için çekici yerler haline getirmede önemli bir rol oynamaktadır (O’Brien vd., 2017). Mesire Yerleri Yönetmeliği, (2013)'de D tipi kent (şehir) ormanı; ormanların öncelikle sağlık, spor, estetik, kültürel ve sosyal fonksiyonlarını halkın hizmetine sunmak, aynı zamanda yurdun güzelliğine katkı sağlamak, toplumun çeşitli spor ve dinlenme ihtiyaçlarını karşılamak, turistik hareketlere imkân vermek ve teknik ormancılık faaliyetleri ile flora ve faunanın da tanıtılarak, özellikle çocuklar ve gençlere orman sevgisi ve bilincinin aşılanması maksadıyla izcilik, doğa yürüyüşü, bisiklet, binicilik ve benzeri etkinlikler ile kır lokantası, kır kahvesi, kültür evleri, yöresel ürün sergi ve satış yeri, amfi tiyatro, çeşitli mini spor alanları ve diğer rekreasyonel yapı ve tesisleri ihtiva eden, il ve ilçelerde ayrılan yerleri ifade eder şeklinde tanımlanmaktadır.

Birçok çalışma, kent ormanlarının insan sağlı̆̆ı ve refahı için büyük bir öneme sahip olduğunu vurgulamaktadır (Bethmann vd., 2018; Bieling vd., 2014;
Coppel \& Wustemann, 2017; Pietila vd., 2015; Völker vd., 2018). Kent ormanları ayrıca şehirler ve yaşayanları üzerinde olumlu ekonomik etkilere de sahiptir (Wolf \& Robbins, 2015). Kent sakinlerinin kentsel doğadan ve kent ormanlarından elde ettiği sayısız fayda, bilimsel literatürde "ekosistem hizmetleri" terimiyle ifade edilmiştir (Baumeister vd., 2020). Ekosistem hizmetleri, doğal ve kültürel ekosistemlerin sürdürülebilirliğinin sağlanması ve doğal kaynakların korunması için kapasitelerinin ve etkileşim ilişkilerinin ortaya konması gereken, ekosistemlerin fonksiyon ve süreçleri sonucunda ortaya çıkan, insanlara doğrudan ya da dolaylı sunulan fayda ve ürünlerdir (Kaya \& Uzun, 2019). Portman, (2013) ekosistem servisleri kavramını "planlamada çevre korumayı öncelik haline getirmenin son umudu" olarak ifade etmiştir (Terzi vd., 2020). Binyıl Ekosistem Değerlendirmesi (MEA), (2005) ekosistem servislerini destekleyici, düzenleyici, kaynak sağlayıcı ve kültürel ekosistem servisleri olarak sınıflandırmıștır.

$\mathrm{Bu}$ çalışmada kent ormanlarının sağladığ ekosistem servislerinin Kafkasör Kent Ormanı (Artvin) örneğinde irdelenmesi amaçlanmıştır. $\mathrm{Bu}$ amaç doğrultusunda arazi çalışmalarında yerinde gözlemler yapılmış ve literatürde yer alan ekosistem servisi parametrelerinin kent ormanı tarafindan hangilerinin ve nasıl karşılandığını tartışılmıştır.

\section{MATERYAL VE METOT}

Çalışma materyalini, Türkiye'nin kuzeydoğusunda yer alan Artvin kentinin merkezine 8 km uzaklıkta olan Kafkasör Kent Ormanı oluşturmaktadır (Şekil 1). Artvin kenti Göğe Komşu Topraklar ve Yeşil Artvin kavramlarıyla özdeşleştirilmiştir. Bu kavramsallaştırmada önemli bir paya sahip olan Kafkasör Kent Ormanı; kenti çevreleyen yeşil kuşağın bir parçasıdır ve kentteki aktif yeşil alan statüsüne sahip nadir alanlardan biridir.

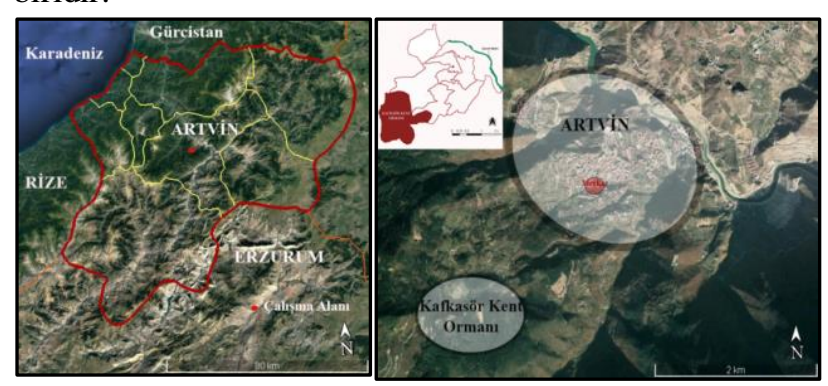

Şekil 1. Çalışma Alanı.

Figure 1. Study area.

Kafkasör Kent Ormanı; 38,35 ha büyüklüğündedir (OGM, 2009). Her mevsim ziyaretçi potansiyeline sahip olan alan özellikle yaz aylarında 
oldukça yoğun kullanılmaktadır. Kafkasör Kent Ormanı'nda piknik alanları, yeme-içme alanları, yürüyüş yolları, festival alanı ve çocuk oyun alanı mevcuttur.

Çalışmada yöntem iki aşamalı olarak yürütülmüştür. İlk aşamada literatürde yer alan ekosistem servisleri parametrelerinin kent ormanı tarafindan karşılanıp karşılanmadığı tartışılmıştır. İkinci aşamayı ise arazi çalışmaları oluşturmaktadır.

Literatürde yer alan ekosistem servisleri bağlamında Binyıl Ekosistem Değerlendirmesi (2005)'in sınıflandırmasından faydalanılarak kaynak sağlayan ekosistem servisleri bağlamında; gida, biyolojik hammadde, dekoratif kaynaklar, biyokimyasallar ve tıbbi ürünler kategorileri; düzenleyici servisler bağlamında; hava kalitesi düzenleme, iklim düzenleme, su akıșı kontrolü, erozyon kontrolü, polenleme kategorileri; destekleyici servisler bağlamında, fotosentez, besin döngüsü ve su döngüsü kategorileri irdelenmiștir. Kültürel ekosistem servisleri bağlamında ise Binyıl Ekosistem Değerlendirmesi, (2005)'in sinıflandırılmasındaki bilgi sistemi, eğitim değeri, ilham, estetik değerler, sosyal ilişkiler, yer ve mekan hissi, rekreasyon ve eko-turizm kategorileri ve Church vd., (2014)'ün kültürel ekosistem servislerinin refah açısından faydaları sınıflandırmasında yer alan sağlık, ekonomi, sosyal bağlantılar, kentsel yeşil altyapıların faydaları ve doğayla bağlantı, duyusal deneyimler (O’Brien vd., 2017) parametreleri irdelenmiștir.

Arazi çalışmalarında çalışma alanındaki mekânların sağladığı ekosistem servisleri Nikon D 7200 fotoğraf makinasıyla fotoğraflanmıştır.

\section{BULGULAR VE TARTIȘMA}

\section{Servisleri \\ Kafkasör Kent Ormanının Sağladığı Ekosistem}

Kaynak Sağlayan Ekosistem Servisleri: Kentlerde, kent ormanları nadir bulunan bitki ve hayvan türleri için yaşam alanıdır, biyolojik çeşitlilik için önem arz etmektedir ve tozlaşma için elzem öneme sahiptir (Baumeister vd., 2020). Kafkasör Kent Ormanı'nda gıda açısından doğadan toplanarak yenebilen meyve türleri ve hayvan türlerini barındırmaktadır. OGM (2009) kent ormanı içerisinde memeli yaban hayvanlarının; yaban tavşanı, sincap, kurt, çakal, tilki, ağaç sansarı, porsuk, ayı, yaban domuzu, karaca olduğunu ifade etmiştir. Kent ormanları kent sakinlerine av hayvanları ve findık, çilek, mantar, şifalı otlar gibi yenilebilir bitkiler sağlar (Baumeister vd., 2020; Garcia-Nietoet vd., 2013; Poe vd., 2014). Kafkasör Kent Ormanı içerisinde mantar türleri ve Vaccinium arctostaphylos L. (ayı üzümü) meyveleri toplanabilmektedir.
Biyolojik hammadde açısından kent ormanından; gerektiğinde hasat yoluyla elde edilen ürünler olan tomruk, kereste ve kâğıt hamuru elde edilebilmektedir.

Dekoratif kaynaklar bakımından ziyaretçiler kent ormanında mevsimsel renklenmenin yanı sıra sonbahar mevsiminde Colchicum speciosum Steven (Vargit çiçeği) ve ilkbaharda ise Rhododendron ponticum L. (Mor çiçekli orman gülü) türlerinin sunduğu renkleri gözlemleyebilirler.

Kent orman1; Picea orientalis Link, Pinus sylvestris L., Abies nordmanniana (Stev.) Spach subsp. normanniana, Rhododendron ponticum L. ve Vaccinium arctostaphylos L. gibi tıbbi ve aromatik bitkilerle biyokimyasal ve tıbbi ürünler bakımından ekosistem servisi sağlamaktadır (Şekil 2).
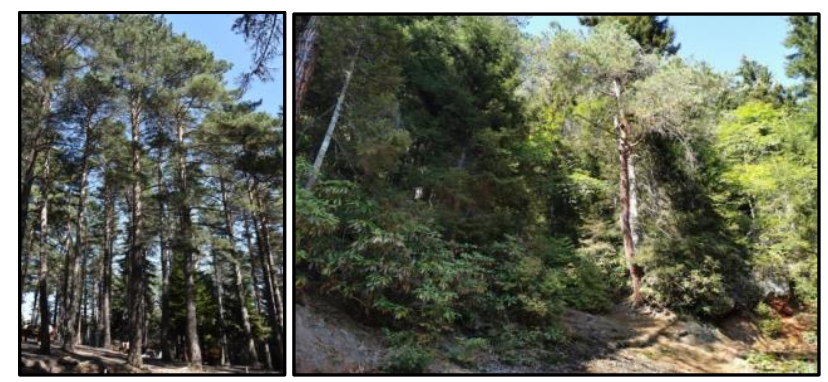

Şekil 2. Kent ormanında yer alan tıbbi ve aromatik bitki birlikleri (Pinus sylvestris L., Picea orientalis Link, Rhododendron ponticum L. ve Vaccinium arctostaphylos L.).

Figure 2. Medicinal and aromatic plant communities in urban forest.

Düzenleyici Ekosistem Servisleri: Pulighe vd., (2016) kent ormanlarının; kent iklimi üzerinde serinletme etkisi gibi olumlu etkileri olduğunu, karbon depoladığını ve erozyonu kontrol ettiğini ifade etmişlerdir. Stolt, (1982) daha geniş toplam yüzey alanı nedeniyle iğne yapraklı ağaçların yaprak döken ağaçlardan daha büyük bir filtreleme kapasitesine sahip olduğunu ancak yaprak döken ağaçlar gazları emmede daha iyi olduğunu ifade ederek hava filitrasyonunda türlerin karışımının en iyi alternatif olduğunu belirtmiştir (Bolund \& Hunhammar, 1999). İğne yapraklı ve geniş yapraklı ağaçların yer aldığı Kafkasör Kent Ormanı hava kalitesini düzenlemede önemli bir paya sahiptir (Şekil 3). OGM (2009) kent ormanının yaklaşık 57 ton karbon depoladığını ve bunun atmosferdeki 209 ton karbondioksite karşılık geldiğini belirtmiştir. Kent ormanı kent iklimi üzerinde olumlu bir etkiye de sahiptir. Araştırmacı tarafindan yerel olarak ölçülen sıcaklık değerlerine bakıldığında kent merkezinde $34^{\circ} \mathrm{C}$ iken kent ormanındaki sıcaklık değerinin $27^{\circ} \mathrm{C}$ ölçülmüştür.

Artvin kenti ve Kafkasör Kent Ormanı oldukça eğimli bir topoğrafya üzerinde kurulmuştur. Bu topoğrafya kent ormanının ve kentin ziyaretçilerine özgün ve eşsiz manzaralar sağlarken toprak kayması gibi olumsuz 
durumların oluşmasına da imkân tanımaktadır. Ancak kent ormanındaki bitki örtüsü su akışı ve erozyon kontrolü noktasında kente önemli servisler sunarak katkı sağlamaktadır.
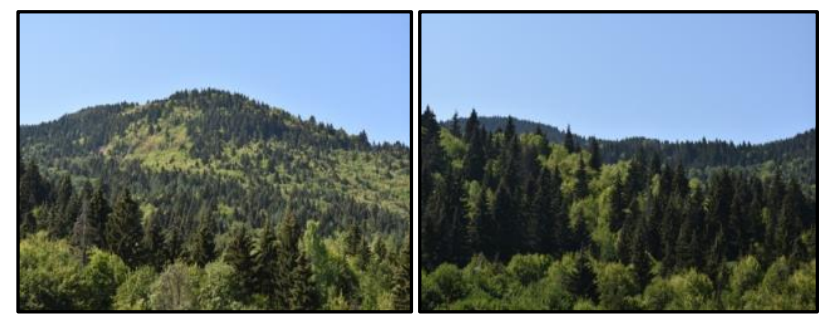

Şekil 3. Kent ormanında yer alan yapraklı ve ibreli türler kompozisyonlar1.

Figure 3. Compositions of deciduous and coniferous species in urban forest.

Kafkasör Kent Ormanı'ndaki kuş türleri; doğu atmacası, çakır kuşu, adi şahin, kızıl şahin, küçük kartal, sakallı akbaba, karasağan, arıkuşu, ibibik, büyük alaca ağaçkakan, kaya kırlangıcı, çayır incikuşu, dağ kuyruksallayanı, kızıl akbaba, gezgin doğan, guguk kuşu, cüce baykuş, puhu, çobanaldatan, kulaklı toygar kuşu, öter ardıç, çekirge çuşu, kuzgun, pembe sığırcık, kar ispinozu, dağ ispinozu'dur (OGM, 2009). Kent ormanları kuşlar, böcekler ve kelebekler gibi polen taşıyıcılar için yaşam alanıdır. Çalışma alanı da bu noktada polenleme açısından ekosistem servisi sağlamaktadır (Şekil 4).

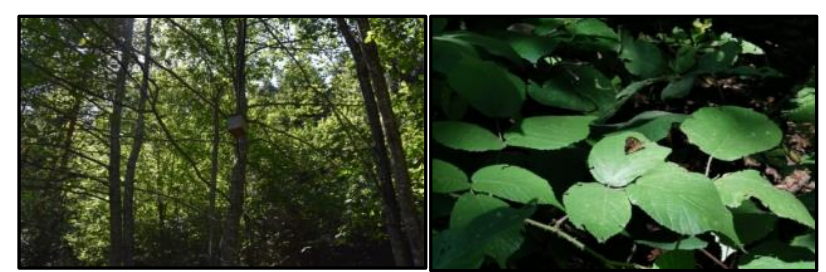

Şekil 4. Kent ormanında polenlemeye yardımcı kuşlar için kuş yuvası ve kelebek görüntüsü.

Figure 4. Image of bird' nest and butterfly that help pollination in urban forest.

Destekleyici Ekosistem Servisleri: Kafkasör Kent Ormanı; herdem yeşil ve yaprak döken türlerin bir arada görülebildiği bir peyzaja sahiptir. Kent ormanında Picea orientalis Link, Pinus sylvestris L., Abies nordmanniana (Stev.) Spach subsp. normanniana, Alnus glutinosa (L.) Gaertner subsp. barbata, Fagus orientalis Lipsky, Castanea sativa Mill., Quercus petraea (Mattuschka) Lieblein, Acer sp., Sorbus sp. gibi ağaçlar ve Vaccinium sp., Rhododendron sp., Viburnum sp., Buxus sp., Rubus sp., Juniperus sp., Empetrum sp. gibi çalı türleri yer almaktadır. $\mathrm{Bu}$ mevcut bitkiler fotosentez yaparak kente oksijen sağlamakta, besin ve su döngüsüne destek olmaktadır.

Kültürel ekosistem servisleri: Kentsel alanlarda, yeşil altyapıların kültürel ekosistem servisleri, kent nüfusu için kilit öneme sahiptir (Benedict \& McMahon, 2002).
Kentsel alanlarda yaşayanlar için çekici ve daha yaşanabilir ortamlar yaratmanın yanı sıra, insanların ziyaret etmeleri, gezmeleri, eğlenmeleri, korumaları ve bakmaları için mekânlar da sağlayabilmektedir (Hartig vd., 2014 O’Brien vd., 2017). Kent ormanlar1, kentlerin yakınında tesis edilmeleri nedeniyle kentte yaşayan bireylerin kısa sürede ulaşabileceği ve kendilerini yenileyebilecekleri aktif yeşil alanlardır. Kafkasör Kent Ormanı kültürel ekosistem servisleri açısından kente, kentte yaşayanlara ve ziyaretçilere birçok servis sağlamaktadır.

Kent ağaçları ve ormanları, kentsel çevre eğitim programlarında belirgin bir şekilde rol oynamaktadır. Kentsel orman ekosistemlerinin yüksek görünürlüğü, değişkenliği ve karmaşıklığı, çevre eğitimi için olağanüstü bir laboratuvar oluşturmaktadır (Dwyer \& Schroeder, 1994; Nowak \& Dwyer, 2007). Bu noktada Kafkasör Kent Ormanı hem bilgi sistemi hem de eğitim açısından kent halkı ve ziyaretçiler için canlı bir laboratuvardır. Artvin Çoruh Üniversitesi'nde eğitim gören öğrenciler (peyzaj mimarlığı, orman mühendisliği, biyoloji bölümleri) için kent ormanı elde ettikleri bilimsel bilgileri alanda görerek pekiştirmede önemli rol oynamaktadır (Şekil 5).

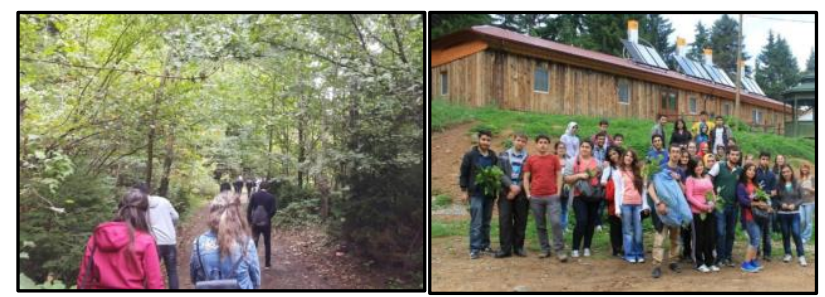

Şekil 5. Kent ormanında öğrencilerle gerçekleştirilen ders uygulamaları.

Figure 5. Lesson practices with students in urban forest.

Kafkasör Kent Ormanı'nın sahip olduğu eşsiz manzaralar, bu alanı kullanan bireyler için bilimsel ve sanatsal açıdan ilham kaynağı oluşturmaktadır. Sanatsal açıdan, manzara resimleri için kaynak olabilirken hem sanatsal hem bilimsel açıdan ise manzaralardaki doğanın sunduğu kompozisyonların kentsel alanlardaki kompozisyonlara yansitılmasında esin kaynağı olabilecektir.

Estetik değerler açısından; Kafkasör Kent Ormanı manzara noktalarına sahiptir. Ayrıca kent sakinleri ve ziyaretçiler kent ormanı içerisinde bitkilerin mevsimsel renklenmelerini gözlemleyebilirler (Şekil 6).

Sosyal ilişkiler bağlamında; Kafkasör Kent Ormanı, kent sakinlerinin ve ziyaretçilerinin karşılıklı sosyal ilişkiler kurabilecekleri mekânlar sağlamaktadır. Kent ormanında yer alan çadırlı kamp mekânları ve piknik alanları sosyal ilişkilerin kurulabildiği mekânlardır (Şekil 7). 


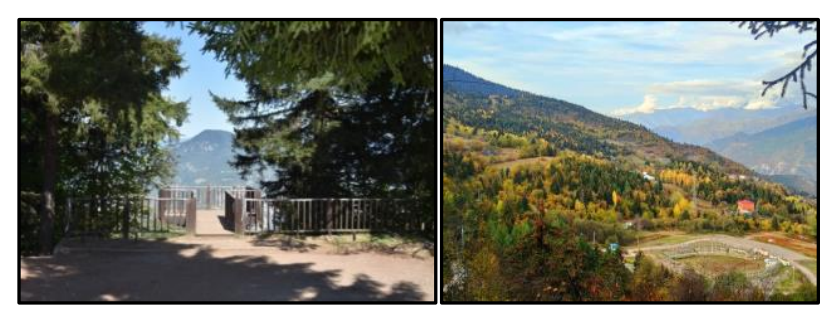

Şekil 6. Kent ormanında bir manzara noktası ve bu manzara noktasından bir sonbahar görüntüsü.

Figure 6. A wiew point in the urban forest and an autumn view from this view point.

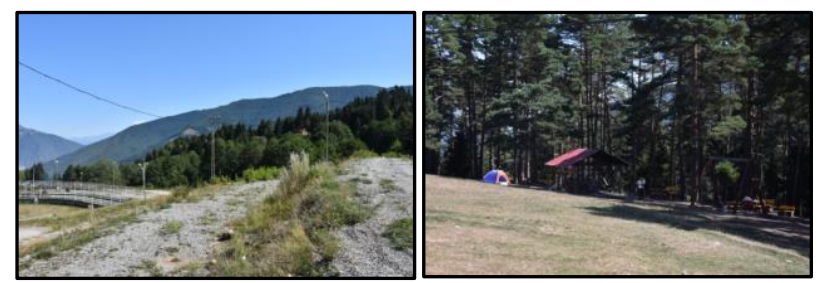

Şekil 7. Kent ormanında özellikle festival zamanı yoğun olarak kullanılan kamp alanı ve piknik alanı.

Figure 7. Camping area especially used extensively during festivals and picnic area in urban forest.

Kafkasör Kent Ormanı kullanıcılarına istedikleri zaman yalnız kalıp kendilerini dinleyebilecekleri, istediklerinde de grup etkinlikleri gerçekleştirebilecekleri yer ve mekânlar sunmaktadır. Bu bazen kent ormanında yer alan bir ağacın gölgesi olabildiği gibi bazen de çeşitli aktiviteleri (oyun oynama, konser dinleme vb.) yerine getirebilecekleri geniş çim yüzeyler ve oturma alanlarıdır (Şekil 8).

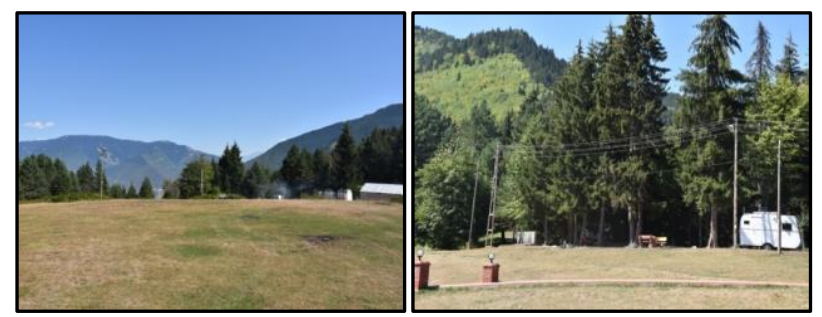

Şekil 8. Kent ormanında yer alan geniş çim yüzeyler ve yalnız kalınabilecek mekanlar.

Figure 8. Wide lawn spaces and places to stay alone in urban forest.

Kent ormanları, kentin estetiğine katkı sağlayan ve kentlerin rekreasyon ihtiyacina cevap vererek bireylerin fiziksel ve zihinsel sağlığının iyileşmesine katkı sağlayan önemli yeșil alanlardır. Rajoo (2020) Japonya'da shinrinyoku" olarak ifade edilen "orman banyosu" anlamına gelen orman terapisi kavramı geliştirildiğini ve bu kavramın fiziksel ve zihinsel sağlığı iyileştirme yeteneğine sahip olduğunun araştırmalarla (örneğin, Hansen vd., 2017; Mao vd., 2017; Song vd., 2017; Kotte vd., 2019; Lyu vd., 2019; Rajoo vd., 2019) ortaya konulduğunu ifade etmiştir.

Kafkasör Kent Ormanı da bireylere rekreasyonel açıdan çeşitli kültürel ekosistem servisleri sağlamaktadır.
Kent ormanı kullanıcıların doğayla baş başa kalabileceği yürüyüş parkurlarına sahiptir. Kullanıcılar bu yürüyüş parkurları üzerinde bitkileri ve yaban hayatını gözlemleme imkânına sahiptir. Ayrıca kent ormanı içerisinde düzenlenen yürüyüş parkuru bitiminde kent ormanı göletlerine ulaşılmakta ve ziyaretçiler bu alanda suyun dinlendirici etkisinden de faydalanabilmektedir (Şekil 9).

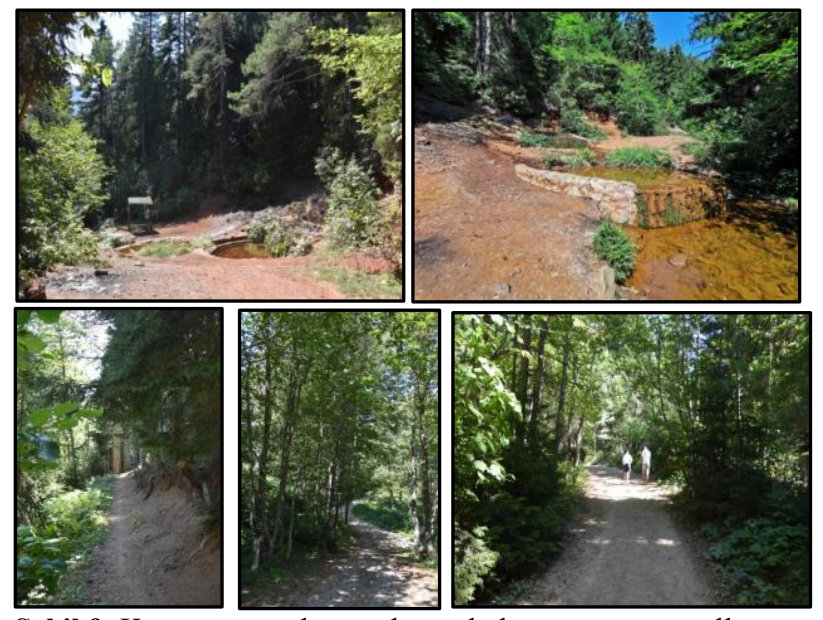

Şekil 9. Kent ormanında yer alan göletler ve yürüyüş yolları. Figure 9. Ponds and walking areas in urban forest.

Kent ormanı içerisinde kullanıcıların konaklama ve yeme-içme aktivitelerini gerçekleştirebilecekleri otel/restoran gibi mekânların yanı sıra farklı alanlarda yer alan piknik alanları da mevcuttur (Şekil 10).
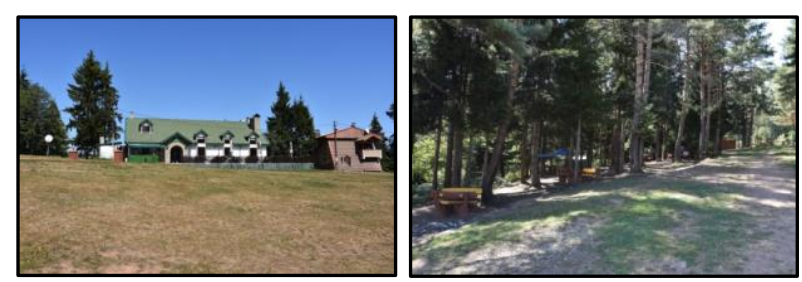

Sekil 10. Kent ormanındaki konaklama ve yeme-içme alanları. Figure 10. Accommodation and eating-drinking areas in urban forest.

Kent ormanında kullanıcıların aileleri ve çocuklarıyla birlikte kaliteli zaman geçirebilecekleri serbest etkinlik alanı ve çocuk oyun alanı yer almaktadır (Şekil 11).
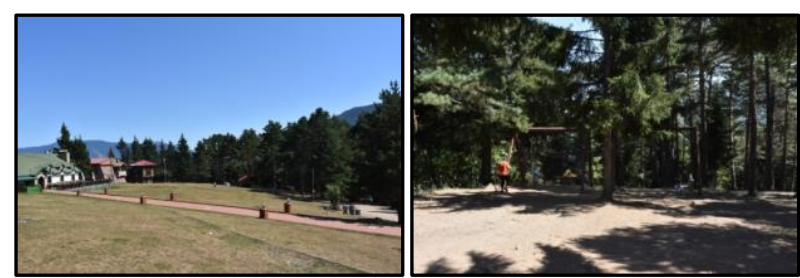

Şekil 11. Kent ormanındaki serbest etkinlik alanı ve çocuk oyun alan1.

Figure 11. Free activity area and playground in urban forest. 
Kent ormanının sarp bir yamaç üzerinde kurulması nedeniyle kullanıcılara farklı manzaraları seyretme ve bu özgün manzaralarda fotoğraf çekme imkânı sunmaktadır. Ayrıca kent ormanı turizm açısından da kente önemli ekonomik katkılar sağlamaktadır. Özellikle kent ormanında düzenlenen festivale çok sayıda yerli ve yabancı turist gelmektedir. Sağlık açısından kent ormanının sunduğu güvenli ve sakin ortam sayesinde bireyler huzur bulmakta ayrıca özgürce fiziksel aktiviteleri yerine getirerek hem fiziksel hem psikolojik açıdan kendini yenileme imkânı bulmaktadır. Kent ormanının temiz havası, doğal ihtişamı, atmosferi ve kuş sesleri, duyusal deneyimler açısından sağladığı servislerdir.

\section{SONUÇ VE ÖNERILLER}

Kent ormanları; kent çevrelerinin monotonluğunu kıran, kentlerdeki yeşil dokuyu güçlendiren ve kent yakın çevresinde olmasından ötürü bireylerin daha kısa süre içerisinde doğayla iletişim kurmasına imkân tanıyan yeşil altyapıların önemli bir parçasıdır. Kent ormanları kentlere, kentlilere ve ziyaretçilerine gıdadan dekoratif kaynaklara, fotosentezden polenlemeye, eğitimden rekreasyona kadar oldukça geniş bir yelpazede ekosistem servisi sağlamaktadır.

Çalışmaya konu edilen Kafkasör Kent Ormanı da Artvin kentine, sakinlerine ve ziyaretçilerine kaynak sağlayan, destekleyici, düzenleyici ve kültürel ekosistem servisleri bağlamında birçok servisi sağlamaktadır. Ancak kent ormanında kültürel ekosistem servisleri açısından bazı eksikliklerin giderilmesi ve bazı eklemelerin yapılması gerekmektedir. Oldukça yoğun bir ziyaretçi potansiyeli olan kent ormanında kentin tanıtımına ve ekonomisine katkısı olacak bir kültür evi planlanmalı ve ayrıca yöresel ürün sergi ve satış alanı kurgulanmalıdır. Önerilen bu alanlar için uygun alanın kent ormanın giriş noktasının olduğu düşünülmektedir. Yürüyüş parkurlarını farklı yaş gruplarının kullanacağı düşünülerek yürüyüş güzergâhı üzerinde her $50 \mathrm{~m}$ 'de bir oturma-dinlenme alanları düzenlenmeli ve yürüyüş parkuru sonunda yer alan göletler çevresinde de oturma-dinleme alanları arttırılmalıdır. Kent ormanında yer alan donatıların (piknik masaları, çeşmeler, çocuk oyun donatıları, yönlendirme levhaları vb.) da bakımı yapılmalıdır.

Ekosistem servislerin sürekliliğinin sağlanabilmesi ve insanların bu servislerden en verimli şekilde yararlanabilmesi için doğru stratejilerin belirlenmesi ve bu stratejiler doğrultusunda planlamaların yapılması ve hatta alan yönteminin bu doğrultuda gerçekleştirilerek alanın sürdürülebilirliğinin sağlanması büyük önem arz etmektedir.

\section{KAYNAKLAR}

Akbari, H. (2002). Shade trees reduce building energy use and $\mathrm{CO}_{2}$ emissions from power plants. Environmental Pollution, 116, 119-126.

Barthel, S., Parker, J. \& Ernstson, H. (2015). Food and green space in cities: A resilience lens on gardens and urban environmental movements. Urban Studies, 52(7), 1321-1338.

Baumeister, C.F., Gerstenberg, T., Plieninger, T. \& Schraml, U. (2020). Exploring cultural ecosystem service hotspots: Linking multiple urban forest features with public participation mapping data. Urban Forestry and Urban Greening, 48, 126561.

Benedict, M.A. \& McMahon, E.T. (2002). Green infrastructure: Smart conservation for the 21st century. Renewable Resources Journal, 20, 1217.

Bethmann, S., Simminger, E., Baldy, J. \& Schraml, U. (2018). Forestry in interaction. Shedding light on dynamics of public opinion with a praxeological methodology. Forest Policy and Economics, 69, 93-101.

Bieling, C., Plieninger, T., Pirker, H. \& Vogl, C.R. (2014). Linkages between landscapes and human well-being: an empirical exploration with short interviews. Ecological Economics, 105, 19-30.

Binyıl Eksosistem Değerlendirmesi (MEA). (2005). Ecosystems and Human Well-being: Synthesis, Millennium Ecosystem Assessment. Island Press, Washington, DC, 137p.

Bogar, S. \& Beyer, K.M. (2015). Green space, violence, and crime: A systematic review. Trauma, Violence and Abuse, 17(2), 160-171.

Bolund, P. \& Hunhammar, S. (1999). Ecosystem services in urban areas. Ecological Economics, 29, 293-301.

Carrus, G., Scopelliti, M., Lafortezza, R., Colangelo, G., Ferrini, F., Salbitano, F., Agrimi, M., Portoghesi, L., Semenzato, P. \& Sanesi, G. (2015). Go greener, feel better? The positive effects of biodiversity on the wellbeing of individuals visiting urban and peri-urban green areas. Landscape and Urban Planning, 134, 221228.

Church, A., Fish, R., Haines Young, R., Mourato, S., Tratalos, J., Stapleton, L., Willis, C., Coates, P., Gibbons, S., Leyshon, C., Potschin, M., Ravenscroft, N., Sanchis-Guarner, R., Winter, M. \& Kenter, J. (2014). UK National Ecosystem Assessment Follow-On. Work Package Report 5: Cultural Ecosystem Servicesand Indicators. UNEP-WCMC, LWEC, UK, 135p.

Conradson, D. (2005). Landscape, care and the relational self: Therapeutic encounters in rural England. Health and Place, 11(4), 337-348.

Coppel, G. \& Wustemann, H. (2017). The impact of urban green space on health in Berlin, Germany: empirical findings and implications for urban 
planning. Landscape and Urban Planning, 167, 410-418.

De Vries, S., Van Dillen, S.M., Groenewegen, P.P. \& Spreeuwenberg, P. (2013). Streetscape greenery and health: Stress, social cohesion and physical activity as mediators. Social Science and Medicine, 94, 26-33.

Dwyer, J. F. \& Schroeder, H. W. (1994). The human dimensions of urban forestry. Journal of Forestry, 92(10), 12-15.

Garcia-Nieto, A.P., Garcia-llorente, M., Iniestaarandia, I. \& Martin-lopez, B. (2013). Mapping forest ecosystem services: From providing units to beneficiaries. Ecosystem Services, 4, 126-138.

Grote, R., Samson, R., Alonso, R., Amorim, J. H., Cariñanos, P., Churkina, G. \& Mikkelsen, T. N. (2016). Functional traits of urban trees: air pollution mitigation potential. Frontiers in Ecology and the Environment, 14(10), 543-550.

Hansen, M.M., Jones, R. \& Tocchini, K. (2017). Shinrinyoku (forest bathing) and nature therapy: A state of the art review. International Journal of Environmental Research and Public Health, 14(8), 1-48.

Harriss, L. \& Hawton, K. (2011). Deliberate self-harm in rural and urban regions: a comparative study of prevalence and patient characteristics. Social Science and Medicine, 73(2), 274-281.

Hartig, T., Mitchell, R. \& De Vries, S. (2014). Nature and health. Annual Review of Public Health, 35, 207228.

Kaya, M.Y. \& Uzun, O. (2019). Ekosistem hizmetleri ve mekânsal planlama ilişkisinin peyzaj planlama çerçevesinde değerlendirilmesi. Düzce Üniversitesi Bilim ve Teknoloji Dergisi, 7, 21662193.

Kotte, D., Li, Q., Shin, W.S. \& Michalsen, A. (2019). International Handbook of Forest Therapy. Cambridge Scholars Publishing, UK, 610p.

La Rosa, D. (2014). Accessibility to greenspaces: GIS based indicators for sustainable planning in a dense urban context. Ecological Indicators, 42, 122-134.

Lafortezza, R., Carrus, G., Sanesi, G. \& Davies, C. (2009). Benefits and well-being perceived by people visiting green spaces in periods of heat stress. Urban Forestry and Urban Greening, 8(2), 97-108.

Lyu, B., Zeng, C., Xie, S., Li, D., Lin, W., Li, N., Jiang, M., Liu, S. \& Chen, Q. (2019). Benefits of a Three-day Bamboo Forest therapy session on the psychophysiology and immune system responses of male College students. International Journal of Environmental Research and Public Health, 16(24), 49-91.

Ma, F. (2020). Spatial equity analysis of urban green space based on spatial design network Analysis (sDNA): A case study of central Jinan, China. Sustainable Cities and Society, 60, 102256.
Mao, G., Cao, Y., Wang, B., Wang, S., Chen, Z., Wang, J., Xing, W., Ren, X., Lv, X., Dong, J., Chen, S., Chen, X., Wang, G. \& Yan, J. (2017). The salutary influence of Forest bathing on elderly patients with chronic heart failure. International Journal of Environmental Research and Public Health, 14(4), 368-387.

Margaritis, E. \& Kang, J. (2017). Relationship between green space-related morphology and noise pollution. Ecological Indicators, 72, 921-933.

Mesire Yerleri Yönetmeliği, 2013. Mevzuat Bilgi Sistemi.

https://www.mevzuat.gov.tr/mevzuat?MevzuatN $\mathrm{o}=17173 \&$ MevzuatTur=7\&MevzuatTertip $=5$. (28.08.2020).

Nowak, D.J. \& Dwyer, J.F. (2007). Understanding the benefits and costs of urban forest ecosystems, In: (Ed: Kuser, J.E.), Urban and Community Forestry in the Northeast, pp. 25-46. USDA Forest Service, Northeastern Research Station, Syracuse, New York.

O'Brien, L., De Vreese, R., Kern, M., Sievänen, T., Stojanova, B. \& Atmis, E. (2017). Cultural ecosystem benefits of urban and peri-urban green infrastructure across different European countries. Urban Forestry and Urban Greening, 24, 236248.

OGM. (2009). Kent Ormanları. T.C. Çevre Ve Orman Bakanlığı Orman Genel Müdürlüğü yayınları,https://www.ogm.gov.tr/ekutuphane/Ya yinlar/Kent\%20Ormanlar\%C4\%B1.pdf. (28.07.2020).

Pietila, M., Neuvonen, M., Borodulin, K., Korpela, K., Sievanen, T. \& Tyrvainen, L. (2015). Relationships between exposure to urban green spaces, physical activity and selfrated health. Journal of Outdoor Recreation and Tourism, 10, 44-54.

Poe, M.R., Lecompte, J., Cmlain, R. \& Hurley, P. (2014). Urban foraging and the relational ecologies of belonging. Social and Cultural Geography, 15, 901-919.

Portman, M.E. (2013). Ecosystem services in practice: challenges to real world implementation of ecosystem services across multiple landscapes: a critical review. Applied Geography, 45, 185-192.

Pulighe, G., Fava, F. \& Lupia, F. (2016). Insights and opportunities from mapping ecosystem services of urban green spaces and potentials in planning. Ecosystem Services, 22, 1-10.

Rajoo, K.S., Karam, D.S. \& Abdul Aziz, N.A. (2019). Developing an effective forest therapy program to manage academic stress in conservative societies: A multi-disciplinary approach. Urban Forestry and Urban Greening, 43, 126353.

Rajoo, K.S., Karam, D.S. \& Abdullah, M.Z. (2020). The physiological and psychosocial effects of forest therapy: A systematic review. Urban Forestry and Urban Greening, 54, 126744. 
Riva, S., Curtis, S., Gauvin, L. \& Fagg, J. (2009). Unravelling the extent of inequalities in health across urban and rural areas: evidence from a national sample in England. Social Science and Medicine, 68, 654-663.

Shin, D-H. \& Lee, K-S. (2005). Use of remote sensing and geographical information system to estimate green space temperature change as a result of urban expansion. Landscape and Ecological Engineering, 1, 169-176.

Song, C., Ikei, H. \& Miyazaki, Y. (2017). Sustained effects of a forest therapy program on the blood pressure of office workers. Urban Forestry and Urban Greening, 27, 246-252.

Stolt, E. (1982). Vegetationens förmaga att minska expositionen för bilavgaser (The ability of vegetation in decreasing exposure to car fumes). Göteborgs Universitet pa uppdrag av Göteborgs Halsovardsavdelning (quoted from Svensson and Eliasson 1997, in Swedish).

Terzi, F., Tezer, A., Turkay, Z., Uzun, O., Köylü, P., Karacor, E., Okay, N. \& Kaya, M. (2020). An ecosystem services-based approach for decision making in urban planning. Journal of Environmental Planning and Management, 63(3), 433-452.

Ulrich, R.S., Bogren, L., Gardiner, S.K. \& Lundin, S. (2018). Psychiatric ward design can reduce aggressive behavior. Journal of Environmental Psychology, 57, 53-66.

Van den Berg, A.E., Maas, J., Verheij, R. A. \& Groenewegen, P.P. (2010). Green space as a buffer between stressful life events and health. Social Science and Medicine, 70(8), 1203-1210.

Völker, S., Heiler, A., Pollmann, T., Classe, T., Hornberg, C. \& Kistemann, T. (2018). Do perceived walking distance to and use of urban blue spaces affect self-reported physical and mental health? Urban Forestry and Urban Greening, 29, 1-9.

Wolf, K.L. \& Robbins, A.S. (2015). Metro nature, environmental health, and economic value. Environmental Health Perspectives, 123, 390398.

Zhang, B., Xie, G., Zhang, C. \& Zhang, J. (2012). The economic benefits of rainwater runoff reduction by urban green spaces: A case study in Beijing, China. Journal of Environmental Management, 100, 65-71. 